\title{
Features of the application of the dumpster- shafer theory when adopting management decisions in construction operations
}

\author{
Denis Pogodin ${ }^{1}$, Konstantin Kuzmin ${ }^{2, *}$, Yuri Shesterikov ${ }^{3}$ \\ ${ }^{1}$ Moscow State University of Civil Engineering, 26, Yaroslavskoe shosse, 109377, Moscow, Russia \\ ${ }^{2}$ Moscow state University of technology and management. K.G. Razumovsky (Smolensk branch), \\ Smolensk region, 77, Lenin str., 215100, Vyazma, Russia \\ ${ }^{3}$ Research Institute for Design, Technology and Construction Expertise, 1A, Novgorodskaya str., \\ 127576, Moscow, Russia
}

\begin{abstract}
The article discusses the features of the application of the Dempster-Shafer theory in the management and planning of construction operations. An example of expert evaluation is given, the most possible reasons for the delay of construction and installation works with the aim of taking them into account when planning have been determined.
\end{abstract}

\section{Introduction}

Management decisions are the result of the synthesis of information about the present to establish the course of development for the future. It can be a product of the thought of one person or a group of people (experts). The effectiveness of management decisions depends primarily on a sufficient scope of reliable and reliable information about the conditions changed during the production process.

Management decisions in construction are divided into technical (change in design development); technological (choice of production methods for construction and installation works); production (organization of the production process), marketing (connection with market activities and sales of products), economic (financial activities, cost reduction of construction and installation work and increased profits) and social ones (improvement of workers' conditions at a construction site, increased safety of labor).

\section{Methods}

Almost all complex managerial tasks in construction require a wide range of different groups of specialists - economists, engineers, marketing specialists, ecologists, etc., and each of these groups, as a rule, solves its specific tasks [1].

At the final stage, when it is necessary to summarize all judgments, interdisciplinary disunity greatly complicates the final decision, and the expert groups can adopt uncompromising positions. Recently, when solving managerial problems involving expert

*Corresponding author:kyzmina_tk@mail.ru 
assessments and fuzzy information, methods of the fuzzy sets theory have become widespread. These methods turned out to be very useful in the case of a high level of uncertainty and a lack of initial information; however, when solving such problems, it becomes necessary to take into account contradictory data obtained on the basis of subjective expert assessments [1].

An alternative approach is the Dempster-Shafer's Evidence theory. An important aspect of this theory is the combination of evidence obtained from multiple sources and the modeling of conflict between them. In addition, this approach solves the problem of measuring confidence [2-6].

\section{Basis of the Dempster-Shafer theory}

Examine set $\Theta=\left\{A_{1} ; A_{2} ; \ldots ; A_{N}\right\}$ of mutually exclusive hypotheses (statements), which is called the area of analysis (hypotheses frame). The power set $\Theta$ is denoted as $2^{\Theta}=$ $\{A \mid A \subseteq \Theta\}$. The basic probability assignment or the mass function (confidence measure) is a function that is represented as $2^{\Theta}$ in the interval $[0 ; 1]$, so that $\mathrm{m}\{\oslash\}=0$, where $\oslash$ is the empty set and $\sum_{A \subseteq \Theta} m(A)=1[7-9]$.

The function of trust and attractiveness is defined as follows.

$$
\begin{gathered}
\operatorname{Bel}(A)=\sum_{\emptyset \neq B \subseteq A} m(B) \forall A \subseteq \Theta ; \\
P l(A)=1-\operatorname{Bel}(\bar{A})=1-\sum_{B \subseteq \bar{A}} m(\bar{A})=\sum_{B \cap A \neq \emptyset} m\{B\} \forall A \subseteq \Theta,
\end{gathered}
$$

where $\operatorname{Bel}(A)$ is the mass sum of the trust of subsets $\mathrm{A}$ or the confidence score $\mathrm{A}$, i.e. measure of the total amount of faith in A and in its subsets;

$\operatorname{Pl}(A)$ is the mass sum of the mistrust of the subset $\mathrm{A}$ or the estimate of attractiveness, i.e. probability measure.

In this case, the interval of evidence is defined as

$$
E I(A)=[\operatorname{Bel}(A) ; 1-\operatorname{Bel}(\bar{A})] \text {, т.e. } \operatorname{Bel}(A) \leq P(A) \leq P l(A) .
$$

The measure of doubt and ignoring or ignorance is calculated by the following formulas:

$$
\begin{gathered}
\operatorname{Dbt}(A)=\operatorname{Bel}(\bar{A})=1-\operatorname{Pl}(A) ; \\
\operatorname{Ign}(A)=\operatorname{Pl}(A)-\operatorname{Bel}(A) .
\end{gathered}
$$

Thus, evidence in the form of subsets $\mathrm{X}$ and $\mathrm{Y}$ are combined by the Dempster rule as the orthogonal sum of two measures. This value is called the added mass and is defined as follows:

$$
\begin{gathered}
m_{1} \otimes m_{2}(A)=k ; \\
k=\frac{1}{1-\sum X \cap Y=\oslash m_{1}(X) m_{2}(Y)},
\end{gathered}
$$

where $k$ is the normalization constant (measure of the conflict between two sets of masses; $\sum_{X \cap Y=\emptyset} m_{1}(X) m_{2}(Y)$ is the conflict between two evidences.

$$
\text { For an empty set } m_{1} \otimes m_{2}(\oslash)=0, A=\oslash \text {. }
$$

If $k^{-1}=0$, then the orthogonal sum does not exist, and the measures $m_{1}$ and $m_{2}$ are called completely mutually exclusive. In general, for the nth number of mass functions $m$ in the set $\Theta$, the conflict will be as 


$$
K=\sum_{\cap_{i=1}^{n} E_{i=\emptyset}} m_{1}\left(E_{1}\right) m_{2}\left(E_{2}\right) \ldots . m_{n}\left(E_{n}\right)>0
$$

and after the combination, the mass function will be

$$
m(A)=\left(m_{1} \otimes m_{2} \otimes \ldots \otimes m_{n}\right)(A)=\frac{1}{1-K} .
$$

\section{Numerical example of the application of the Dempster-Shafer theory in the management of construction operations}

It is necessary to determine (predict) possible causes that may lead to a delay of construction and installation work in order to make appropriate management decisions.

The initial data for solving the assigned task, will be the opinions of expert groups on the possibility (weight) of hypotheses (reasons) for delaying construction and installation work at a specific construction site: a- weather conditions; b - constrained conditions; csupply of material and technical resources (disruption); $d$ - human factor.

This article takes into account the evidence (opinion) of two groups of experts (Table 1).

Table 1. Initial mass functions.

\begin{tabular}{|c|c|}
\hline First group of experts & Second group of experts \\
\hline $\mathrm{m}_{1}(\mathrm{~d})=0,3$ & $\mathrm{~m}_{2}(\mathrm{c})=0,2$ \\
\hline $\mathrm{m}_{1}(\mathrm{c})=0,5$ & $\mathrm{~m}_{2}(\mathrm{~b})=0,6$ \\
\hline $\mathrm{m}_{1}(\mathrm{~b})=0,2$ & $\mathrm{~m}_{2}(\mathrm{a})=0,2$ \\
\hline
\end{tabular}

\section{Results}

Thus, at the initial stage, two evidences are combined in the form of subsets of hypotheses $\mathrm{X}=\{\mathrm{b}, \mathrm{c}, \mathrm{d}\}$ and $\mathrm{Y}=\{\mathrm{a}, \mathrm{b}, \mathrm{c}\}$ according to the Dempster's rule

$$
\mathrm{m}_{1} \otimes \mathrm{m}_{2}(\mathrm{Z})=\frac{\sum \mathrm{X} \cap \mathrm{Y}=\mathrm{Z} \mathrm{m}_{1}(\mathrm{X}) \mathrm{m}_{2}(\mathrm{Y})}{1-\sum \mathrm{X} \cap \mathrm{Y}=\varnothing \mathrm{m}_{1}(\mathrm{X}) \mathrm{m}_{2}(\mathrm{Y})} .
$$

In Tables 2 and 3 (gray cells) the mass functions, for which the masses are equal to zero, are not given, since they do not allow generating new mass values $m_{3}=m_{1} \otimes m_{2}$ during the combination (as 0 multiplied by any number gives 0 ).

Table 4 presents the combination $\mathrm{m}_{1}$ and $\mathrm{m}_{2}$, as well as intermediate data: the common subsets - $(\mathrm{X} \cap \mathrm{Y})$ and the product of their weight values are determined.

Table 2. The results of calculations to determine the plausibility and attractiveness by X.

\begin{tabular}{|l|c|c|c|c|c|c|}
\hline & \multicolumn{5}{|c|}{ Model 1 } \\
\hline \multicolumn{1}{|c|}{$\mathrm{X}$} & $\mathrm{m}_{1}$ & $\mathrm{Bel}(\mathrm{X})$ & $\mathrm{Dbt}(\mathrm{Bel}(\mathrm{X}))$ & $\mathrm{Pl}(\mathrm{X})$ & $\mathrm{EI}[\mathrm{Bel}(\mathrm{X}), \mathrm{Pl}(\mathrm{X})]$ \\
\hline$\{\mathrm{b}\}$ & 0,2 & 0,2 & $\mathrm{X}=\{\mathrm{c} ; \mathrm{d}\}$ & 0,8 & 0,2 & {$[0,2 ; 0,2]$} \\
\hline$\{\mathrm{c}\}$ & 0,5 & 0,5 & $\mathrm{X}=\{\mathrm{b} ; \mathrm{d}\}$ & 0,5 & 0,5 & {$[0,5 ; 0,5]$} \\
\hline$\{\mathrm{d}\}$ & 0,3 & 0,3 & $\mathrm{X}=\{\mathrm{b} ; \mathrm{c}\}$ & 0,7 & 0,3 & {$[0,3 ; 0,3]$} \\
\hline$\{\mathrm{b} ; \mathrm{c}\}$ & 0 & 0,7 & $\mathrm{X}=\{\mathrm{d}\}$ & 0,3 & 0,7 & {$[0,7 ; 0,7]$} \\
\hline$\{\mathrm{b} ; \mathrm{d}\}$ & 0 & 0,5 & $\mathrm{X}=\{\mathrm{c}\}$ & 0,5 & 0,5 & {$[0,5 ; 0,5]$} \\
\hline$\{\mathrm{c} ; \mathrm{d}\}$ & 0 & 0,8 & $\mathrm{X}=\{\mathrm{b}\}$ & 0,2 & 0,8 & {$[0,8 ; 0,8]$} \\
\hline$\Theta=\{\mathrm{b} ; \mathrm{c} ; \mathrm{d}\}$ & 0 & 1,0 & $\mathrm{X}=\varnothing$ & 0 & 1,0 & {$[1,0 ; 1,0]$} \\
\hline$\varnothing$ & 0 & 0 & $\mathrm{X}=\{\mathrm{b}, \mathrm{c}, \mathrm{d}\}$ & 1 & 0 & {$[0 ; 0]$} \\
\hline
\end{tabular}


Table 3. The results of calculations to determine the plausibility and attractiveness by Y.

\begin{tabular}{|l|c|c|c|c|c|c|}
\hline \multicolumn{1}{|c|}{} & \multicolumn{5}{|c|}{ Model 2 } \\
\hline$\{\mathrm{Y}\}$ & $\mathrm{m}_{2}$ & $\operatorname{Bel}(\mathrm{Y})$ & $\mathrm{Dbt}(\mathrm{Bel}(\mathrm{Y}))$ & $\mathrm{Pl}(\mathrm{Y})$ & $\operatorname{EI}[\operatorname{Bel}(\mathrm{Y}) ; \mathrm{Pl}(\mathrm{Y})]$ \\
\hline$\{\mathrm{b}\}$ & 0,2 & 0,2 & $\mathrm{Y}=\{\mathrm{b} ; \mathrm{c}\}$ & 0,8 & 0,2 & {$[0,2 ; 0,2]$} \\
\hline$\{\mathrm{c}\}$ & 0,6 & 0,6 & $\mathrm{Y}=\{\mathrm{a} ; \mathrm{c}\}$ & 0,4 & 0,6 & {$[0,6 ; 0,6]$} \\
\hline$\{\mathrm{a} ; \mathrm{b}\}$ & 0,2 & 0,2 & $\mathrm{Y}=\{\mathrm{a} ; \mathrm{b}\}$ & 0,8 & 0,2 & {$[0,2 ; 0,2]$} \\
\hline$\{\mathrm{a} ; \mathrm{c}\}$ & 0 & 0,8 & $\mathrm{Y}=\{\mathrm{c}\}$ & 0,2 & 0,8 & {$[0,8 ; 0,8]$} \\
\hline$\{\mathrm{b} ; \mathrm{c}\}$ & 0 & 0,4 & $\mathrm{Y}=\{\mathrm{b}\}$ & 0,6 & 0,4 & {$[0,4 ; 0,4]$} \\
\hline$\Theta=\{\mathrm{a} ; \mathrm{b} ; \mathrm{c}\}$ & 0 & 1,0 & $\mathrm{Y}=\varnothing$ & 0 & 1,0 & {$[1,0 ; 1,0]$} \\
\hline$\varnothing$ & 0 & 0 & $\mathrm{Y}=\{\mathrm{a} ; \mathrm{b} ; \mathrm{c}\}$ & 1 & 0 & {$[0 ; 0]$} \\
\hline
\end{tabular}

Table 4. Class combination results.

\begin{tabular}{|l|l|l|l|l|l|l|l|l|}
\hline & \multicolumn{2}{l}{$\mathrm{m}_{2}(\mathrm{a})=0,2$} & $\mathrm{~m}$ & $\mathrm{~m}(\mathrm{~b})=0,6$ & $\mathrm{~m} 2(\mathrm{c})=0,2$ & $\mathrm{~m}_{2}=0$ \\
\hline $\mathrm{m}_{1}(\mathrm{~b})=0,2$ & $\varnothing$ & 0,04 & $\{\mathrm{~b}\}$ & 0,12 & $\varnothing$ & 0,04 & $\{\mathrm{~b}\}$ & 0 \\
\hline $\mathrm{m}_{1}(\mathrm{c})=0,5$ & $\varnothing$ & 0,1 & $\varnothing$ & 0,30 & $\{\mathrm{c}\}$ & 0,10 & $\{\mathrm{c}\}$ & 0 \\
\hline $\mathrm{m}_{1}(\mathrm{~d})=0,3$ & $\varnothing$ & 0,06 & $\varnothing$ & 0,18 & $\varnothing$ & 0,06 & $\{\mathrm{~d}\}$ & 0 \\
\hline $\mathrm{m}_{1}(\mathrm{a})=0,0$ & $\{\mathrm{a}\}$ & 0 & $\{\mathrm{~b}\}$ & 0 & $\{\mathrm{c}\}$ & 0 & $\varnothing$ & 0 \\
\hline
\end{tabular}

Next, we find the values

$$
\sum_{X \cap Y=\emptyset} m_{1}(X) m_{2}(Y)=0,04+0,04+0,1+0,30+0,06+0,18+0,06=0,78
$$

and the value of the normalization factor

$$
1-\sum_{\mathrm{X} \cap \mathrm{Y}=\emptyset} \mathrm{m}_{1}(\mathrm{X}) \mathrm{m}_{2}(\mathrm{Y})=0,22 .
$$

Determine:

$$
\begin{gathered}
\mathrm{m}_{1} \otimes \mathrm{m}_{2}(\{\mathrm{a}\})=0 ; \mathrm{m}_{1} \otimes \mathrm{m}_{2}(\{\mathrm{~b}\})=0,12 / 0,22 ; \\
\mathrm{m}_{1} \otimes \mathrm{m}_{2}(\{\mathrm{c}\})=0,10 / 0,22 ; \mathrm{m}_{1} \otimes \mathrm{m}_{2}(\{\mathrm{~d}\})=0 ; \\
\mathrm{m}_{1} \otimes \mathrm{m}_{2}(\{\oslash\})=0 .
\end{gathered}
$$

The above values give the opportunity to calculate new confidence values $m_{3}$ based on the combinations $\mathrm{m}_{1}$ and $\mathrm{m}_{2}$ (Table 5).

Table 5. Results for determining new confidence values.

\begin{tabular}{|l|l|l|l|l|}
\hline \multicolumn{2}{|c|}{} & \multicolumn{3}{|c|}{ Models `1 and 2 } \\
\hline \multicolumn{1}{|c|}{$\mathrm{Z}$} & \multicolumn{3}{|c|}{$\operatorname{Dbt}(\mathrm{Bel}(\mathrm{Z}))$} & $\mathrm{EI}[\mathrm{Bel}(\mathrm{Z}), \mathrm{Pl}(\mathrm{Z})]$ \\
\hline$\{\mathrm{a}\}$ & 0 & $\mathrm{Z}=\{\mathrm{b} ; \mathrm{c} ; \mathrm{d}\}$ & 1,0 & {$[0,0]$} \\
\hline$\{\mathrm{b}\}$ & 0,54 & $\mathrm{Z}=\{\mathrm{a} ; \mathrm{c} ; \mathrm{d}\}$ & 0,45 & {$[0,54 ; 0,54]$} \\
\hline$\{\mathrm{c}\}$ & 0,45 & $\mathrm{Z}=\{\mathrm{a} ; \mathrm{b} ; \mathrm{d}\}$ & 0,54 & {$[0,45 ; 0,45]$} \\
\hline$\{\mathrm{d}\}$ & 0 & $\mathrm{Z}=\{\mathrm{a} ; \mathrm{b} ; \mathrm{c}\}$ & 1,0 & {$[0 ; 0]$} \\
\hline$\{\mathrm{a}, \mathrm{b}\}$ & 0 & $\mathrm{Z}=\{\mathrm{c} ; \mathrm{d}\}$ & 0,45 & {$[0,54 ; 0,54]$} \\
\hline$\{\mathrm{a}, \mathrm{c}\}$ & 0 & $\mathrm{Z}=\{\mathrm{b} ; \mathrm{d}\}$ & 0,54 & {$[0,45 ; 0,45]$} \\
\hline
\end{tabular}




\begin{tabular}{|l|l|l|l|l|}
\hline$\{\mathrm{a}, \mathrm{d}\}$ & 0 & $\mathrm{Z}=\{\mathrm{b} ; \mathrm{c}\}$ & 1,0 & {$[0 ; 0]$} \\
\hline$\{\mathrm{b}, \mathrm{c}\}$ & 0 & $\mathrm{Z}=\{\mathrm{a} ; \mathrm{d}\}$ & 0,0 & {$[1,0 ; 1,0]$} \\
\hline$\{\mathrm{b}, \mathrm{d}\}$ & 0 & $\mathrm{Z}=\{\mathrm{a} ; \mathrm{c}\}$ & 0,45 & {$[0,54 ; 0,54]$} \\
\hline$\{\mathrm{c}, \mathrm{d}\}$ & 0 & $\mathrm{Z}=\{\mathrm{a} ; \mathrm{b}\}$ & 0,54 & {$[0,45 ; 0,45]$} \\
\hline$\{\mathrm{a}, \mathrm{b}, \mathrm{c}\}$ & 0 & $\mathrm{Z}=\{\mathrm{d}\}$ & 0,0 & {$[1,0 ; 1,0]$} \\
\hline$\{\mathrm{a}, \mathrm{b}, \mathrm{d}\}$ & 0 & $\mathrm{Z}=\{\mathrm{c}\}$ & 0,45 & {$[0,54 ; 0,54]$} \\
\hline$\{\mathrm{a}, \mathrm{c}, \mathrm{d}\}$ & 0 & $\mathrm{Z}=\{\mathrm{b}\}$ & 0,54 & {$[0,45 ; 0,45]$} \\
\hline$\{\mathrm{b}, \mathrm{c}, \mathrm{d}\}$ & 0 & $\mathrm{Z}=\{\mathrm{a}\}$ & 0,0 & {$[1,0 ; 1,0]$} \\
\hline$\Theta=\{\mathrm{a}, \mathrm{b}, \mathrm{c}, \mathrm{d}\}$ & 0 & $\mathrm{Z}=\{\varnothing\}$ & 0,0 & {$[1,0 ; 1,0]$} \\
\hline$\varnothing$ & 0 & $\mathrm{Z}=\{\varnothing\}$ & 1,0 & {$[0 ; 0]$} \\
\hline
\end{tabular}

As a result, the intervals obtained after the combinations are formed:

$$
\begin{aligned}
& \operatorname{El}(\{c ; d\})=[0,45 ; 0,45] ; \\
& \operatorname{El}(\{a ; b\})=[0,54 ; 0,54] .
\end{aligned}
$$

These intervals show the most probable causes, namely "a" - weather conditions and "b" - constrained conditions, which, according to experts, will affect the duration of the construction and installation works at a given construction site.

\section{Conclusion}

The Depster-Shafer theory allows processing and classifying data in the face of uncertainty, and also provides a simple mechanism to compensate for the lack of data using the so-called Deckster combination rule.

A definite disadvantage of the Depster-Shaefer theory methods is their computational complexity, but the capabilities of modern computing technology usually allow one to overcome this problem. Due to the noted advantages, data processing methods based on the Depster-Shafer theory are becoming increasingly common in data classification, decision making, including management, and in risk assessment.

\section{References}

1. A.V. Matveev, V.I. Kotov, M.I. Mushkudiani, The use of information technology in habitat management (Saint-Petersburg, 2005)

2. S.I. Zukhovitsky, I.A. Radchik, Mathematical methods of network planning (Moscow, 2010)

3. D. Dubois, A. Prad, Theory of possibilities. Application to knowledge representation in computer science (Moscow, 1990)

4. G.A. Shafer, Mathematical Theory of evidence (Princeton, 1976) A.M. Polyakov, In Informatics: problems, methodology, technology 1, 243-244 (2014)

5. C. Romessis, A. Kyriazis, K. Mathioudakis, IGTI/ASME Turbo Expo. 9, GT200727043 (2007)

6. G. Vachtsevanos, L.F.L. Roemer, A.M. Hess, B. Wu, Intelligent Fault Diagnosis and Prognosis for Engineering Systems (Wiley, 2006)

7. R.C. Lou, M.G. Kay, IEEE Transactions of System, Man and Cybernetics 1, 901-931 (1989)

8. A.P. Dempster, The Annals of Statistics 1, 342-349 (1967) 